\title{
Strength performance of unreinforced brick masonry walls under flexo-compression load. Analytical methods
}

\author{
Ernest Bernat-Maso ${ }^{a}$ and Lluís Gil ${ }^{b}$ \\ Department of Strength of Materials and Structures in Engineering \\ Universitat Politècnica de Catalunya UPC, Barcelona TECH. \\ C/ Colom 11, TR45 D.137, 08222 Terrassa, Spain \\ aernest.bernat@upc.edu, ${ }^{\mathrm{b}}$ lluis.gil@upc.edu
}

Keywords: Load-bearing brick masonry walls, Second order bending; Analytic calculation; Standards calculation; Experimental comparison.

\begin{abstract}
The structure of many historical buildings relies on unreinforced masonry load-bearing walls. In the case of large slenderness or significant eccentricity of the vertical compressive loads the mechanism formation failure mode is likely. Considering the second order bending effects and the tensile strength of the masonry is essential to accurately calculate the load-bearing capacity of these structures, which is required for maintenance tasks. An analytical methodology has proposed with this aim. This original method, the Southwell plot method and the formulations from two standard codes (ACI-530 and Eurocode-6) are applied to calculate the resistance of 18 experimentally tested walls to conclude that the proposed methodology brings correct results, the standards are conservative and the Southwell plot method is the most suitable for the analysis of the considered cases but it is not always applicable.
\end{abstract}

\section{Introduction}

Masonry is one of the most used materials in historical buildings testimonies worldwide, and the load-bearing wall is the most common structural element. However, the masonry typology has evolved along the ages, from the first dry stone masonry structures, which might date back to 15000 years [1], to the brick masonry industrial buildings of the $18^{\text {th }}$ and $19^{\text {th }}$ centuries.

Regardless of the age, preserving and maintaining the historical buildings which belong to our cultural heritage is mandatory. Thus, assuring the structural safety these buildings is an essential task. In addition, it seems recommendable to keep the usefulness of these constructions so the safety requirements have to be fulfilled not only under the existing loading configuration but also under other applied loads, which might be associated with new uses of the building.

Calculating the load-bearing capacity of brick masonry walls in an accurate and easy way requires limiting the studied case to particular loading configurations, boundary conditions or material definition. Taking into account that structural walls mostly work under compression forces transmitted by the roof or slabs, it seems necessary to consider the case of eccentrically applied compression loads. Moreover, the eccentricity of these loads may contribute to generate second order bending effects which might ease the mechanism formation collapse. This failure mode is sudden and becomes a real hazard to be avoided for the most slender walls, which are common in the modernist buildings of Barcelona among many other historical buildings in non-seismic areas.

In the early 1930's, Southwell proposed a hybrid method consisting on using experimentally determined data about the structural response of imperfect columns to predict their load-bearing capacity. It has to be considered a reasonable alternative to determine the load-bearing capacity of existing walls. The procedure considers only the buckling failure mode and requires measuring the elastic response of the structure (see [2]). A few researches have been done to improve the Southwell Plot method although it is worth mentioning the research of Singer [3] who allowed to extend the application of this method by considering the possibility of a plastic buckling, which occurs before the buckling load because of the reduction of the rigidity of the material. 
According with professor Magenes [4], the first pure analytical researches about the compressive response of masonry walls go back to 1930's and contributed to the later on development of analytical formulations like the investigation on the buckling phenomenon of masonry walls performed by Haller [5]. Among others, the analytical approach proposed by Gross et al. [6] has to be mentioned too. This formulation resulted from fitting the experimental results of hundreds of full-scale tests. Considering experimental tests to adjust analytical formulations was a common trend. In this line, the experiments of Kirtschig and Anstötz [7] also resulted in an analytical formulation for calculating the load-bearing capacity of brick masonry walls against buckling phenomenon. Finally and because of the impact of the publications, it is also important to highlight the two papers by Yokel $[8,9]$ which stand the as basis for relating the cross sectional strength with the load-bearing capacity of the wall including the effect of the slenderness and eccentricity.

In the last decades the non-linear response of the masonry has also been taken into account in some approaches. For example, in the work by Romano et al. [10], the De Falco's proposal [13] on the stability of columns or the description of the compressive response included in the paper by Mura [13]. However, the tensile strength was only considered in a few researches, like the one carried out by Lu et al. [14]. Finally, Foti [15] analysed the out-of-plane performance considering the brick shape. At the beginning of this century, the geometric non-linear response has been considered in the calculation of masonry walls. Thus, the proposed methods dealt with the buckling phenomenon. However, it has been observed that the most sophisticated the analytical methods are, the less useful they are for practitioners Because of this, an easy but accurate method for calculating brick masonry walls under eccentric compressive loads is herein presented, validated with experimental cases and compared with the results from applying the formulation of the standards Eurocode-6 and ACI-530.

\section{Methodology and scope}

The proposed analytical methodology (called $2^{\text {nd }}$ order bending calculation later on) is validated by calculating the load-bearing capacity of several walls, which were experimentally tested in a previous research [16]. This comparison allows limiting the application range of the methodology. In addition, the Southwell plot method and the standards Eurocode-6 and ACI-530 are also applied to calculate the same walls in order to provide alternatives to the proposed analytical formulation. The considered structural configuration is represented in Fig. 1. A compared analysis of the accuracy of each method is finally presented.

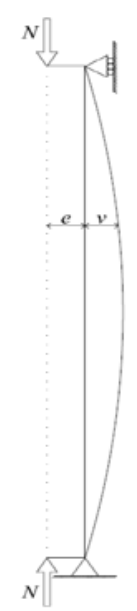

Fig. 1 Second order deformation of an eccentrically loaded column

The main characteristics of the experimentally tested walls considered for the validation of the presented analytical method can be found in [15]. The walls of the H, M and S series have been taken into account. All were built with solid ceramic pieces and brick layering mortar. The compressive strength of the masonry was $18.2 \mathrm{MPa}, 12.9 \mathrm{MPa}, 13.7 \mathrm{MPa}$ for the walls $\mathrm{W} \# 1$, W\#2-5, W\#6-9 of the H-series, and 10.8MPa for the M-series and S-series. The flexural strength of the 
masonry was $0.36 \mathrm{MPa}$ for all walls except W\#1 (0.23MPa). The Young's modulus was 780MPa for all walls. The theoretical dimensions were $132 \mathrm{~mm}$ thickness, $900 \mathrm{~mm}$ width and $2700 \mathrm{~mm}, 1650 \mathrm{~mm}$ and $1000 \mathrm{~mm}$ height for $\mathrm{H}, \mathrm{M}$ and $\mathrm{S}$ series respectively, although real dimension were used to better adjust the experimental results. More detailed data is presented in [15].

Eurocode-6 (EC-6). The current standard for masonry structures in Europe takes into account the boundary conditions inside the slenderness parameter whereas the eccentricity one considers the eccentricity of the axial load, the geometric irregularities of the wall and the out-of-plane loading effects. It is also worth mentioning that EC-6 calculates the load-bearing capacity taking into account the axial, bending and buckling phenomenon together.

ACI-530. The current standard in the USA is based on empirical data obtained from experimental campaigns which have been used to adjust the mathematical formulation. Unlike Eurocode-6, ACI-530 checks the three possible phenomena (axial, bending and buckling) separately. This method assumes a linear stress distribution but the limit stress is empirically defined. ACI-530 does not consider the tensile strength of the masonry in the calculation of the load-bearing capacity. Thus, it is expected to outcome in conservative results for the most slender cases.

$2^{\text {nd }}$ order bending calculation. The main features of this proposed method are considering the second order bending effects and taking into account the tensile strength of the masonry. In addition, the compressive response of the masonry is considered to be linear elastic, which is not commonly accepted. However, the accuracy of the results presented later on suggest that this approximation is valid for calculating walls which failed by mechanism formation. This linear elastic response hypothesis eases the implementation of the calculation of the second order effects, which might be more influent on the load-bearing capacity than the material non-linear response in compression for the most slender walls whose failure mode is associated with a mechanism formation. Finally, this methodology assumes that the walls behave like columns regarding the lateral response. The comparison walls are pinned at both ends, so the total eccentricity, $e_{\text {total }}$, at mid-height can be calculated with Eq. 1, where $e$ is the initial eccentricity of the load, $h_{e f}$ is the effective height (distance between rotation points at the ends of the wall), $N$ is the applied load, $E$ the Young's modulus of the masonry and $I$ the inertia of the cross section.

$$
e_{\text {total }}=e \cdot\left(\frac{1}{\cos \left(\frac{h_{\text {Bff }}}{2} \cdot \sqrt{\frac{N}{E x}}\right)}\right) .
$$

Thus, the theoretical applied bending moment can be calculated for each loading step by multiplying the axial load, $N$, by the total eccentricity, $e_{\text {total }}$. Gathering these data an axial-bending interaction curve was drawn and intersected with the curves representing the stress limit criterion. The intersection point between the response curve and a limit criteria curve is the calculated loadbearing capacity.

The curves associated with the stress limit criterion were calculated by assuming the following hypotheses: linear strain distribution along the cross section thickness; linear stress distribution in both tensile and compressed areas; and failure criteria when the maximum compressive stress reached the compressive strength of the masonry $f_{c}$, see Eq. 2, or when the tensile stress reached the value of the tensile strength of the masonry joints $f_{t}$, see Eq. 3 . In these equations $b$ and $t$ are the width and thickness of the wall respectively and $M$ the bending moment.

$$
\begin{aligned}
& M=\frac{f_{c} b t^{2}}{6}+\frac{N t}{6}, \\
& M=\frac{f_{t} b t^{2}}{6}-\frac{N t}{6} .
\end{aligned}
$$


The procedure to obtain the load-bearing capacity by intersecting the calculated theoretical response with the imposed failure criteria is shown in Fig. 2. It has to be remarked that dimensionless variables were defined for comparison purposes. Thus, the axial force, $N$, is divided by the compressive strength of the cross section under uniform compression $\left(N_{u}=b t f_{c}\right)$, and the calculated bending moment, $M$, is divided by $N_{u} \cdot t / 8$.

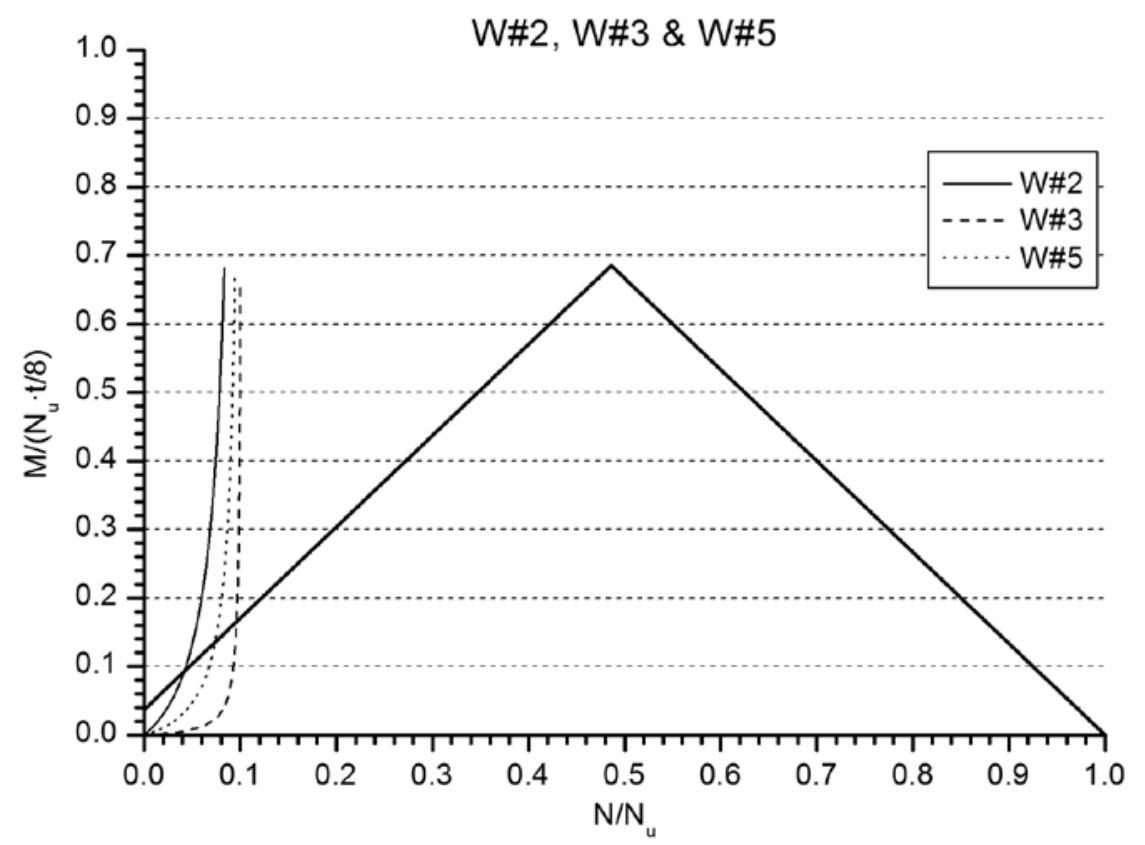

Fig. 2 Second order axial-bending response intersected with the failure criteria

Southwell plot method. This is a hybrid method used for predicting the load-bearing capacity of structural elements which are likely to fail because of buckling phenomena and show an elastic response. This consists on assuming that there is a relationship (Eq. 4) between the lateral deflection, $h$, and the applied load, $N$, which depends on the critical load, $P_{c r}$ and the initial midheight lateral deformation, $a$. Thus, applying Southwell plot method requires measuring the response of the structural element for low or moderate loads (non-destructive). Finally, when plotting $h$ versus $h / N$ in y and x axis respectively, a straight line is obtained and the slope of this line is the load-bearing capacity of the wall.

$$
h \approx \frac{a}{\frac{P_{\text {cor }}-1}{N} .}
$$

The applicability of the Southwell Plot method depends on the scattering of the measured data. It has been noticed that the points of the plot should be linear fitted with a regression coefficient greater than 0.8 to obtain reliable results. A detailed explanation of the method can be consulted in Bažant and Cedoline [2].

\section{Results and discussion}

The results obtained by applying the different considered methodologies are summarised in Table 1. It is observed that the most accurate results are provided by the Southwell plot method for all series. However, this procedure cannot be applied in 4 of the considered cases (marked with $*$ sign in Table 1) because the scattering of the experimental data did not allow fitting a linear regression. Comparing the pure analytical procedures (EC-6, ACI-530 and $2^{\text {nd }}$ order), it has to be noticed that the proposed analytical method, which considers the second order bending effects ( $2^{\text {nd }}$ order), provides the most accurate results for the walls of the $\mathrm{H}$ and M series. EC-6 is the most conservative 
method for all cases and ACI-530 brings the most accurate results for the S-series walls among the pure theoretical methods.

Table 1. Load-bearing capacity calculated with analytical methods and relative error

\begin{tabular}{|c|c|c|c|c|c|c|c|c|c|c|c|}
\hline \multirow{2}{*}{ Type } & \multirow{2}{*}{ Wall } & \multirow{2}{*}{$e[\mathrm{~mm}]$} & \multicolumn{5}{|c|}{$N_{\max }[k N]$} & \multicolumn{4}{|c|}{ Error $[\%]$} \\
\hline & & & $E C-6$ & ACI-530 & Southwell & $2^{\text {nd }}$ order & Experimental & $E C-6$ & ACI-530 & Southwell & $2^{\text {nd }}$ order \\
\hline \multirow{8}{*}{$\mathrm{H}$} & W\#1 & 5.6 & 0.0 & 117.0 & $(*)$ & 115.5 & 172.3 & 100.0 & 30.9 & $(*)$ & 33.0 \\
\hline & W\#2 & 19.6 & 0.0 & 53.8 & 63.6 & 63.7 & 68.7 & 100.0 & 18.1 & 3.3 & 7.2 \\
\hline & W\#3 & 1.2 & 0.1 & 88.9 & 176.0 & 142.4 & 136.7 & 99.9 & 33.5 & 31.5 & 4.1 \\
\hline & W\#5 & 7.0 & 0.0 & 76.2 & $(*)$ & 37.2 & 242.7 & 100.0 & 68.2 & $(*)$ & 13.4 \\
\hline & W\#6 & 33.7 & 0.0 & 50.8 & 29.0 & 86.1 & 32.8 & 100.0 & 69.4 & 3.3 & 37.4 \\
\hline & W\#7 & 13.1 & 0.0 & 114.3 & 168.7 & 106.0 & 137.5 & 100.0 & 15.2 & 25.3 & 19.8 \\
\hline & W\#8 & -7.6 & 0.0 & 150.4 & 152.0 & 58.8 & 132.2 & 100.0 & 16.3 & 17.5 & 47.8 \\
\hline & W\#9 & 21.5 & 0.0 & 82.1 & 107.8 & 72.9 & 112.7 & 100.0 & 25.2 & 1.8 & 87.4 \\
\hline \multirow{7}{*}{ M } & W\#10 & 0.2 & 66.6 & 224.3 & 320.1 & 373.0 & 425.7 & 84.3 & 47.1 & 24.5 & 12.4 \\
\hline & W\#11 & 13.9 & 13.1 & 96.2 & 319.1 & 159.4 & 372.9 & 96.5 & 74.1 & 14.0 & 57.2 \\
\hline & W\#12 & 1.6 & 73.2 & 285.4 & 413.4 & 352.4 & 472.8 & 84.5 & 39.4 & 12.3 & 25.5 \\
\hline & W\#13 & 31.8 & 0.2 & 44.5 & 91.9 & 60.4 & 85.4 & 99.8 & 46.9 & 9.7 & 29.3 \\
\hline & W\#14 & 21.2 & 3.9 & 119.8 & 558.0 & 104.3 & 520.3 & 99.2 & 76.9 & 7.6 & 80.0 \\
\hline & W\#15 & 29.0 & 0.5 & 53.3 & 260.5 & 65.3 & 238.5 & 99.8 & 77.5 & 10.0 & 72.6 \\
\hline & W\#16 & 19.5 & 5.5 & 161.7 & 540.5 & 115.2 & 410.0 & 98.6 & 60.4 & 32.4 & 71.9 \\
\hline \multirow{3}{*}{$S$} & W\#18 & 20.8 & 118.9 & 297.2 & $(*)$ & 238.0 & 804.4 & 85.2 & 63.0 & $(*)$ & 70.4 \\
\hline & W\#19 & 30.3 & 34.6 & 141.0 & $(*)$ & 59.2 & 687.1 & 95.0 & 79.4 & $(*)$ & 91.4 \\
\hline & W\#20 & 33.0 & 21.9 & 111.3 & 165.1 & 44.9 & 153.6 & 85.6 & 27.0 & 8.2 & 70.8 \\
\hline
\end{tabular}

$(*)$ The experimental data did not allow calculating this value.

It has to be remarked that the proposed methodology works better for the most slender walls $(\mathrm{H}$ series) or the ones with the load applied at larger eccentricity. This fact fits with the initial aim of the developed methodology which was intended to accurately calculate the load-bearing capacity of the masonry walls which were expected to fail due to mechanism formation (instability or buckling phenomenon). Thus, the obtained results show that it is important to take into account the second order deformation in the calculation of the load-bearing capacity of the most slender brick masonry walls. However, the obtained error in the application of the $2^{\text {nd }}$ order methodology in contrast with the accuracy of the Southwell plot method, when applicable, suggest that calculating the response of real walls is complex due to the heterogeneity of the materials and the geometric imperfections. In fact, Southwell plot method counts on part of the real experimental response of each wall to predict the corresponding load-bearing capacity.

The standard method that achieves more accurate results is ACI-530. In fact, it is better than the proposed $2^{\text {nd }}$ order method for the less slender walls (S-series). It might be related with the fact that the second order effect is far less significant in these cases than for the most slender walls $(\mathrm{H}$ series). In addition, it has to be remarked that considering the tensile strength of the masonry in the $2^{\text {nd }}$ order method has been useful to obtain more accurate results for the $\mathrm{H}$ and $\mathrm{M}$-series walls.

Finally, it has to be remarked that the error obtained with the $2^{\text {nd }}$ order method is within the scattering range of the experimental input data for the $\mathrm{H}$ and $\mathrm{M}$-series cases, so the accuracy of this methodology is enough to be used as a design or assessment tool.

\section{Conclusions}

After implementing an analytical methodology aimed to consider the second order bending effects and the tensile strength of the masonry at calculating the load-bearing capacity of unreinforced brick masonry walls subjected to eccentric compressive loads, it can be concluded that the proposed method provides accurate results.

The obtained results suggest that it might be recommendable to include the second order bending effects in the calculation of the load-bearing capacity of the most slender walls or those subjected to more eccentric loads, or what is the same, for the cases which are expected to fail by mechanism formation. 
The application of the Southwell plot points out that this method might me the most suitable for calculating the load-bearing capacity of existing masonry walls which could be tested.

Finally, the comparison with Eurocode- 6 and ACI-530 codes suggest that the results provided by these standards are conservative for the cases which are expected to fail by mechanism formation.

\section{References}

[1] H. Gallegos, O. Ramírez, Chapter 1: Las estructuras de mampostería, in: Edif. Mampostería Para La Vivienda, 2nd ed., Fundación ICA, A.C, Mexico D.F., 2003: pp. 1-21.

[2] Z.P. Bažant, L. Cedolin, Stability of structures: elastic, inelastic, fracture and damage theories, World Scientific, 2010.

[3] J. Singer, On the applicability of the Southwell plot to plastic buckling, Exp. Mech. 29 (1989) 205-208.

[4] G. Magenes, Comportamento delle strutture murarie sotto carichi verticali. Corso di dottorato sulle Costruzioni in Muratura. (2009).

[5] P. Haller, Die knickfestigkeit von Mauerwerk aus künstlichen Steinen, Schweizerische Bauzeitung. 67 (1949).

[6] J.G. Gross, R.D. Dikkers, J.C. Grogen, Recommended practice for engineered brick masonry, Mc Lenon, 1969.

[7] K. Kirtschig, W. Asntötz, Buckling tests on masonry, in: Proc. 9th Int. Brick/Block Mason. Conf., IBMAC, Berlin, 1991: pp. 202-209.

[8] F.Y. Yokel, Strength of load bearing masonry walls, J. Struct. Div. 97 (1971) 1593-1609.

[9] F.Y. Yokel, Stability and load capacity of members with no tensile strength, J. Struct. Div. 97 (1971) 1913-1926.

[10]F. Romano, S. Ganduscio, G. Zingone, Cracked nonlinear masonry stability under vertical and lateral loads, J. Struct. Eng. 119 (1993) 69-87.

[11]A. De Falco, M. Lucchesi, Stability of columns with no tension strength and bounded compressive strength and deformability. Part I: large eccentricity, Int. J. Solids Struct. 39 (2002) 6191-6210.

[12] A. Defalco, M. Lucchesi, No tension beam-columns with bounded compressive strength and deformability undergoing eccentric vertical loads, Int. J. Mech. Sci. 49 (2007) 54-74.

[13] I. Mura, Stability of nonlinear masonry members under combined load, Comput. Struct. 86 (2008) 1579-1593.

[14] M. Lu, A. Schultz, H. Stolarski, Analysis of the Influence of Tensile Strength on the Stability of Eccentrically Compressed Slender Unreinforced Masonry Walls Under Lateral Loads, J. Struct. Eng. 130 (2004) 921.

[15] D. Foti. Shape Optimization of Rectified Brick Blocks for the Improvement of the out-of-Plane Behavior of Masonry. International Journal of Mechanics, vol. 7, Issue 4, (2013), 417-424.

[16]E. Bernat, L. Gil, P. Roca, C. Sandoval, Experimental and numerical analysis of bendingbuckling mixed failure of brickwork walls, Constr. Build. Mater. 43 (2013) 1-13. 